\title{
EDUCAÇÃO INFANTIL, DIVERSIDADE ÉTNICO-RACIAL E PRINCÍPIOS ESTÉTICOS: CONTRIBUTOS DAS POÉTICAS DE ARTISTAS NEGRAS À FORMAÇÃO DOCENTE
}

\author{
Greice Duarte de Brito SiLVA \\ Universidade Federal Fluminense (UFF), Niterói, Rio de Janeiro, Brasil \\ LUCIANA ESMERALDA OSTETTO \\ Universidade Federal Fluminense (UFF), Niterói, Rio de Janeiro, Brasil
}

\begin{abstract}
Resumo: Este artigo apresenta uma proposta de encontros-ateliê, realizados com professoras de Educação Infantil negras, com o objetivo de mapear seus caminhos de formação estética. Estruturados em torno da partilha de poéticas de artistas negras, os encontros-ateliê constituíram-se como espaço-tempo para narrativas autobiográficas, de modo a sustentar a premissa de que é necessário abrir espaço para a escuta de narrativas que afirmem (re)existências singulares-plurais. Questões sobre diversidade étnico-racial e princípios estéticos nas propostas para a Educação Infantil articulam-se e compõem o contexto sobre o qual a discussão é tecida. O foco está na formação docente, pois compreende-se que a proposição de pedagogias da diversidade, decoloniais e de re-existência, passa, necessariamente, pela docência e seus repertórios.
\end{abstract}

Palavras-chave: Pedagogia da Diversidade. Professoras Negras. Formação Docente. Princípios Estéticos.

PeLA EDUCAÇÃO: OUTROS GESTOS, PALAVRAS E VIVÊNCIAS

"Olha, ela tem o cabelo como o meu!" exclamou a menina na creche. Ela estava deslumbrada ao ver a sua imagem refletida no livro que a estagiária tinha em mãos. Eu estava próxima o suficiente para testemunhar a alegria e o brilho nos olhos da menina quando reparou no livro "As tranças de Bintou". Aquela alegria genuína, aquele olhar de identificação, calaram fundo em minha alma. Comovida, meus olhos se encheram d'agua. Eu e a estagiária nos entreolhamos e, em silêncio, confirmamos: representatividade importa, é vital! Tudo aconteceu há mais de dez anos. Até hoje aquele olhar está aceso em mim.

Tudo aconteceu há mais de dez anos!

Narrativa compartilhada em FIAR Círculo de Estudo... (2020, n. p.) 
Até hoje, ainda não conseguimos garantir às crianças negras o direito à existência em plenitude, à construção de uma autoimagem positiva, com acesso a referentes, símbolos e práticas que portem representatividade, afirmem identidades e confiram dignidade às diferenças. Para o reconhecimento e o acolhimento da diversidade étnico-racial, a educação cumpre um papel essencial. É por meio da educação, inspira-nos a pensar o patrono da educação brasileira, que podemos ampliar nossa visão de mundo e nos organizar para atuar nele de forma crítica e humanizadora: "Como processo de conhecimento, formação política, manifestação ética, procura da boniteza, capacitação científica e técnica, a educação é prática indispensável aos seres humanos e deles específica na História como movimento, como luta" (FREIRE, 2001, p. 10).

Nesses termos, a educação é prática necessária ao enfrentamento da violência e da discriminação - racistas, classistas, sexistas, transfóbicas -, que negam ao outro o direito de existir em suas diferenças. É pela educação, balizada pelos princípios éticos, políticos e estéticos, de que nos fala Paulo Freire (2004), que podemos inspirar a criação de outros gestos, de outras palavras e vivências a favor da diversidade nas escolas, e fundar pedagogias comprometidas com o combate a toda manifestação discriminatória, não importa se trabalhamos com crianças, jovens ou adultos.

Na Educação Infantil, campo no qual se situa o presente artigo, os mesmos princípios éticos, políticos e estéticos são enunciados como basilares para a constituição das propostas pedagógicas a serem desenvolvidas com as crianças de zero a seis anos, em creches e pré-escolas. O texto do Parecer $N^{\circ} 20$, de 11 de novembro de 2009, que recomenda a aprovação das Diretrizes Curriculares Nacionais para a Educação Infantil DCNEI (BRASIL, 2009a), explicita com clareza os significados de tais princípios: princípios éticos estão relacionados à valorização da autonomia, da responsabilidade, da solidariedade e do respeito ao bem comum, ao meio ambiente e às diferentes culturas, identidades e singularidades; os políticos dizem respeito aos direitos de cidadania, do exercício da criticidade e do respeito à ordem democrática; e os princípios estéticos evidenciam a valorização da sensibilidade, da criatividade, da ludicidade e da diversidade de manifestações artísticas e culturais (BRASIL, 2009a).

Ao ampliarmos o olhar para o texto legal, compreendemos que contemplar os referidos princípios pode ser traduzido como: respeitar as diferentes referências e identidades culturais, proteger a dignidade da criança como pessoa, como sujeito em sua condição humana plena. Significa também apoiar as crianças, desde cedo e ao longo de todas as suas experiências educacionais, nos seus interesses e nas suas curiosidades pelo conhecimento do mundo, possibilitar o acesso a diferentes linguagens e, sobretudo, contribuir para o fortalecimento de sua autoestima e, inclusive, para a aceitação e para o acolhimento das diferenças no convívio com as pessoas. Além disso, das questões ainda não superadas, testemunhamos, no Parecer $N^{\circ} 20 / 2009$, a formulação de orientações que oferecem uma boa direção à revisão e à fundamentação de práticas:

A valorização da diversidade das culturas das diferentes crianças e de suas famílias, por meio de brinquedos, imagens e narrativas que promovam a construção por elas de uma relação positiva com seus 
SILVA, G. D. de B.; OSTETTO, L. E.

grupos de pertencimento, deve orientar as práticas criadas na Educação Infantil ampliando o olhar das crianças desde cedo para a contribuição de diferentes povos e culturas. Na formação de pequenos cidadãos compromissada com uma visão plural de mundo, é necessário criar condições para o estabelecimento de uma relação positiva e uma apropriação das contribuições históricoculturais dos povos indígenas, afrodescendentes, asiáticos, europeus e de outros países da América, reconhecendo, valorizando, respeitando e possibilitando o contato das crianças com as histórias e as culturas desses povos (BRASIL, 2009a, p. 10).

A relação com a promoção da igualdade racial, que diz respeito ao combate ao racismo e às discriminações étnico-raciais, de gênero, socioeconômicas e religiosas, estão claramente enunciadas nas orientações para a organização curricular. Da mesma maneira, a dimensão cultural das ações educativas, que deve refletir nas práticas pedagógicas cotidianas, é destacada de modo a reafirmar que as formas e os conteúdos culturais medeiam a relação da criança consigo mesma e contribuem, assim, para a constituição de seus processos de construção de identidade. Segundo o Art. $8^{\circ}$ da Resolução № 5, de 17 de dezembro de 2009, que regulamentou o Parecer No 20/2009, respeitando os direitos das crianças, a proposta pedagógica deve assegurar:

VIII - a apropriação pelas crianças das contribuições históricoculturais dos povos indígenas, afrodescendentes, asiáticos, europeus e de outros países da América;

IX - o reconhecimento, a valorização, o respeito e a interação das crianças com as histórias e as culturas africanas, afro-brasileiras, bem como o combate ao racismo e à discriminação [...] (BRASIL, 2009b, p. 2-3).

Crianças, no dia a dia, em creches ou pré-escolas, expressam necessidades e interesses múltiplos, bem como são diversas suas histórias de vida e suas formas de ser e de estar em relação, de conhecer e de expressar o mundo, de viver suas infâncias. Ter essa clareza leva-nos a afirmar que a complexidade dos processos, pelos quais as crianças se constituem, aprendem e se desenvolvem, exige um professor atento, responsável, que se faça interlocutor, que cultive a escuta sensível e proponha tempos e espaços que assegurem, tal como referenciado no texto legal, o direito das crianças às múltiplas formas de expressão e o acesso a bens e patrimônios culturais que contribuam para a ampliação de seus repertórios (BRASIL, 2009a, 2009b).

Como garantir os princípios determinados pelas DCNEI? Como fazer valer, nos projetos pedagógicos da Educação Infantil, o acesso aos patrimônios histórico-culturais e às práticas que caminhem para o rompimento de relações de dominação étnico-racial? As escolhas pedagógicas são feitas de acordo com o que professores conhecem e valorizam; assim sendo, com relação à garantia de acesso aos bens e aos patrimônios culturais e artísticos, será fundamental o reconhecimento, a valorização e o respeito às histórias e às culturas africanas e afro-brasileiras. Os professores precisam, então, conhecer tais bens e patrimônios para que suas escolhas pedagógicas sejam pautadas a favor da diversidade. 
Já está referendado que uma oportunidade para a constituição da autoestima das crianças negras é a inserção, nas propostas pedagógicas, de artistas negros, de forma contextualizada, o que é fundamental, pois contribui, também, para uma ruptura da palidez do sistema da arte (SANTOS, 2019). Trazer referências de artistas negros provoca outras aprendizagens, coloca-nos o desafio de pensarmos "estéticas decoloniales", para utilizar expressões de Achinte (2017, p. 55), inaugurando movimentos que revelem a existência de diferentes formas de ver o mundo e a possibilidade de pintá-lo de diversas cores, de forma a contribuir com a re-existência do que historicamente foi subtraído. Práticas pedagógicas que garantam experiências e interação das crianças com diversificadas manifestações de música, artes plásticas e gráficas, cinema, fotografia, dança, teatro, poesia e literatura produzidas por homens e mulheres negros são imprescindíveis.

Como apontam algumas pesquisas (MARTINS; LOMBARDI, 2015; OSTETTO; SILVA, 2018), no percurso formativo docente, em cursos regulares, o contato com a arte é raro, ou mesmo ausente, e, de modo geral, há poucas oportunidades para a ampliação de seus repertórios estéticos para as experiências de fruição e de produção artísticoculturais. Se há essa lacuna relacionada à arte, no contexto da formação docente, qual seria a situação com relação aos conhecimentos das culturas baseadas na africanidade? Será que os professores e as professoras da Educação Infantil conhecem, e compartilham, obras e artistas além dos modelos hegemônicos coloniais, pautados no padrão branco-europeu? Há protagonistas negros nas referências pedagógicas de docentes que atuam na Educação Infantil?

Essas questões formuladas e a argumentação tecida como introdução, neste artigo, estão na base de uma pesquisa em andamento e servem-nos de guias para estruturar e desenvolver alguns pontos decorrentes da discussão posta.

\section{A DIMENSÃO ESTÉTICO-ÉTICA DAS PROPOSTAS PEDAGÓGICAS PARA A EDUCAÇÃO INFANTIL}

O Art. $9^{\circ}$ das DCNEI - Resolução № 5/2009 -, pauta a importância de práticas pedagógicas que "[...] possibilitem vivências éticas e estéticas com outras crianças e grupos culturais, que alarguem seus padrões de referência e de identidades no diálogo e reconhecimento da diversidade [...]" (BRASIL, 2009b, p. 4). De tal forma, os projetos pedagógicos devem ser atravessados pelos encontros com manifestações artísticoculturais plurais, de modo a contribuir não apenas para ampliar as referências e a composição de repertórios diversos das crianças, mas para validar a pluralidade de saberes e de fazeres. Há a orientação, mas como fazê-lo? Na empreitada de criar condições para que sejam efetivadas as diretrizes, é preciso considerarmos que:

A educação estética, assim como a educação das relações étnicoraciais, não acontece em dias marcados, em uma lição, em uma atividade. É uma tarefa cotidiana, contínua, envolvendo todos os aspectos organizacionais: tempos, espaços (e, neles, a decoração), atividades, materiais, brinquedos (OSTETTO, 2017, p. 60). 
SILVA, G. D. de B.; OSTETTO, L. E.

Por formação estética, podemos entender os atravessamentos sensíveis que contribuem para a ampliação dos sentidos, constituição de repertórios artístico-culturais ou ainda tessituras de identidades em diferentes temporalidades da vida humana. Diz respeito a como somos afetados e podemos afetar nas relações com o mundo, na cultura, na natureza, na arte. A formação estética, conforme discutido no âmbito da pesquisa em desenvolvimento, diz respeito

[...] por um lado, [ao] modo como nossos sentidos vão sendo afetados no percurso de nossas interações com a sociedade, a cultura, a natureza; por outro lado, [às] possibilidades de refinamento de tais sentidos, da ampliação do nosso repertório artístico-cultural, das oportunidades de aguçar a sensibilidade, de afetar e de ser afetado pelas coisas do mundo (OSTETTO, 2019, p. 10).

Tal concepção de formação estética se entrelaça à perspectiva que toma por base as chamadas linguagens expressivas, que inauguram uma prática pedagógica na qual a arte é ampliada para uma visão que congrega as linguagens simbólicas, poéticas, expressivas. Nesses termos, garantir, no cotidiano da Educação Infantil, a presença das linguagens poéticas, "[...] caracterizadas pelos aspectos expressivo ou estético, como a música, o canto, a dança ou a fotografia" (VECCHI, 2013, p. 63), pressupõe a organização de propostas que incluam tempos, espaços e materiais nos quais, pelos quais e com os quais as crianças tenham oportunidades para dar vazão à curiosidade e à pesquisa, que possam formular questões e sair em busca de suas hipóteses. Enfim, propostas que ampliem possibilidades de experiências e de expressão sobre o processo de conhecimento, tecidas na relação com o mundo, de modo a construir conexões. Como disse a atelierista italiana, a dimensão estética desenvolve-se no exercício de

[...] interrogar e indagar o mundo, construindo pontos e relações entre experiências e linguagens diversas, para tomar em estreita relação os processos cognitivos e aqueles expressivos, em contínuo diálogo com uma pedagogia que procura trabalhar sobre as conexões e não sobre as separações dos saberes (VECCHI, 2007, p. 138-139).

O diálogo com a arte, como campo de conhecimento, é pressuposto, mas não único, pois cultura e natureza, em sua complexidade, são territórios de experimentações dos sentidos, pelos quais experiências estéticas podem ser afiadas e refinadas em relações significativas com diferentes campos da vida e de conhecimento. Tudo que está ao nosso redor, fora ou dentro da escola, nos afeta, em maior ou menor grau, e contribui para aguçar ou embaçar percepções, desenvolver ou conter os sentidos.

Sem dúvida, o papel de professoras e de professores na educação das infâncias é estratégico. São elas e eles que produzem e negociam os currículos escolares, que organizam os espaços e os tempos, que dispõem ao acesso das crianças objetos culturais e simbólicos, abrem ou fecham janelas de significação. São elas e eles que, por meio dos expedientes que lhes competem, podem colocar em prática ações educativas comprometidas, em maior ou menor grau, com as crianças pequenas e com a construção de sua identidade racial e cultural; que podem se contrapor a políticas 
educacionais excludentes, injustas e genocidas, assumindo a luta em defesa dos direitos das crianças, da liberdade e da diversidade.

Compreendermos o poder da ação docente é também não descuidarmos de sua formação. Se pretendemos uma educação para a diversidade, fundada na educação das relações ético-raciais, além da formação específica, sustentada na legislação em curso e nos conceitos já sistematizados, a dimensão estética é igualmente necessária, haja vista que a ética está a ela integrada. A filósofa Nadja Hermann (2005), em seu livro Ética e estética: a relação esquecida, evidencia a contribuição da experiência estética na ampliação de sentidos e de relações mais arejadas com o mundo: a abertura para a diversidade dos modos de ser, de pensar, de fazer, abre caminho para o reconhecimento do outro, para as diferenças que nos constituem e, assim, para a disposição de aprender a se relacionar com elas de forma empática e generosa, sem desejar eliminá-las.

Ética e estética, concluímos, são elementos decisivos para propostas pedagógicas a serem desenvolvidas na Educação Infantil, etapa da Educação Básica que acolhe grupos de crianças heterogêneos, marcados, não raro, por desigualdades econômicas, sociais e culturais. Assim, como já apontado por Ostetto (2019, p. 6): "Atitudes interculturais, generosas e empáticas são exigências da docência". Dessa forma, lembramos o importante documento que hoje baliza as proposições curriculares para a Educação das Relações Étnico-Raciais (BRASIL, 2004), que aponta três princípios para conduzir as ações: consciência política e histórica da diversidade; fortalecimento de identidades e de direitos; ações educativas de combate ao racismo e a discriminações, os quais exigem dos sistemas de ensino e dos estabelecimentos de Educação Básica, nos diferentes níveis, mudanças de mentalidade, de modos de pensar e agir.

A conscientização de que a educação, em todos os níveis, é desafiada pela diversidade provoca-nos a compor uma teoria educacional que destaque aquilo que nos une, sem perder de vista o que nos diferencia. $O$ debate acerca das questões raciais e a análise da realidade desafiam-nos a uma discussão criadora capaz de produzir uma pedagogia da diversidade (GOMES, 2017), pois tensiona, desse modo, a pedagogia tradicional. Desde o estudo dos saberes emancipatórios, construídos e articulados pelo Movimento Negro, até as determinações legais a favor de políticas que fortaleçam a educação das relações étnico-raciais, temos elementos que nos ajudam a cultivar outros pensamentos e a formular conhecimentos que vinculam as práticas sociais e as formas de aprender.

Nessa empreitada, professoras e professores cumprem um papel político e pedagógico decisivo. Como produtoras(es) de saberes e de fazeres curriculares, como curadoras(es) pedagógicos a quem cabe organizar tempos, espaços e materiais que materializam os desenhos curriculares, professoras e professores podem facilitar ou dificultar o acesso das crianças ao conjunto de saberes de diferentes povos, suas manifestações culturais, seu patrimônio histórico e artístico. Nesse ponto, referendamos a necessidade de propostas de formação docente nas quais os aspectos sensíveis e cognoscíveis estejam entrelaçados, em que a razão não se sobreponha à sensibilidade, mas a integre, em que a história de vida seja, também, matéria formativa, na medida em que, ao afirmar a existência na enunciação do vivido, fertilize outras práticas: narrar é preciso! 
SILVA, G. D. de B.; OSTETTO, L. E.

NA FORMAÇÃO DOCENTE: REMEMORAR E NARRAR PARA AFIRMAR A EXISTÊNCIA

Em uma casa, aprendi o lugar da estética na vida de pessoas negras pobres do campo. Lá a lição que tive foi que devemos entender a beleza como força a ser produzida e imaginada. Os mais velhos nos transmitiram a ideia de que saímos da escravidão de modo a ocupar esse espaço livre, e que tínhamos que criar um mundo que renovasse o espírito, que o tornasse provedor de vida.

bell hooks (2019, posição 2471)

É por meio de atos de memória e do exercício de narrar que as histórias de vida, concebidas como construções biográficas, "representação construída da existência" (DELORY-MOMBERGER, 2008, p. 93), podem ser textualizadas e, no enredo constituído, oferecer não apenas um retrato do vivido, mas oportunidades formativas.

A narrativa é um fio que sustenta o percurso da pesquisa que desenvolvemos, referenciada no aporte teórico-metodológico das abordagens (auto)biográficas, um específico campo de investigação "[...] que se interessa pela maneira com a qual os indivíduos dão uma forma às suas experiências, com a qual eles comunicam as situações e os eventos de suas existências, com a qual eles inscrevem o curso de suas vidas no seu ambiente histórico e social" (DELORY-MOMBERGER, 2008, p. 93).

Se a narrativa é um fio, a maneira de traçá-lo, de matizá-lo, carrega em si uma dimensão estética própria do narrador. $\mathrm{O}$ autor colombiano Adolfo Albán Achinte (2017), ao tratar de memórias e de cosmovisões em perspectivas estéticas decoloniais, observa que: "Lo decolonial de lo estético nos reta a desprendernos de las narrativas que nos niegan la existencia y nos exige apuntar a reconocer los procesos antes que encasillarnos en los productos" (ACHINTE, 2017, p. 36). Sim, é preciso nos distanciar de narrativas que nos negam a existência, assim como também é necessário abrirmos espaços para a escuta do que facilmente nos escapa e, por isso, procurar nos deixarmos capturar pela reflexão do exercício de rememorar. Escutarmos, com todos os nossos sentidos e não apenas com a audição, as histórias que constituem uma vida tem sido um caminho fértil para a pesquisa com professoras e professores de Educação Infantil, na perspectiva de reconhecermos processos e acolhermos narrativas que afirmem existências singulares-plurais.

$\mathrm{Na}$ pesquisa que deu base para o presente artigo, interessou-nos ouvir narrativas de professoras negras que atuam na Educação Infantil, de forma a interpelar seus caminhos de existência e/ou re-existência sensível, caminhos de formação estética, pelos quais a imaginação e a percepção foram cultivadas e as capacidades criativas e expressivas foram potenciadas ou refinadas. Narrar histórias de formação estética docente envolve o ato de rememorar fontes e pontes de sensibilidade ao longo da vida, atentar para os encontros e os desencontros do caminho, para os modos como os sentidos do narrador foram sendo afetados e, por meio deles, de corpo inteiro, como foram afetando seus contextos de vida. É uma narrativa-busca, na qual aquele que escuta se faz testemunha dos processos formativos e também interlocutor atento. 
Aprendemos com a tradição africana que narrativas são geradoras de movimento e ritmo, vida e ação de acordo com o poder criador da fala humana. Ela também nos dá vitalidade para conduzir a investigação, de modo a ampliar referências e dispositivos de geração e de análise de dados. Segundo Bâ (2010, p. 172): "Do mesmo modo, sendo a fala a exteriorização das vibrações das forças, toda manifestação de uma só força, seja qual for a forma que assuma, deve ser considerada como sua fala. É por isso que no universo tudo fala: tudo é fala que ganhou corpo e forma".

No traçado teórico-metodológico da investigação em andamento, procuramos articular a tradição oral africana às abordagens (auto)biográficas, as quais partem da importância de narrativas enunciadas pelas pessoas sobre como vivem, compreendem e enfrentam os desafios sociais de produzir a existência. As histórias que alguém conta a alguém inauguram um tempo de descobrir, uma afirmação com possibilidades de reconhecimento e de interpretação de percursos próprios.

Outro ponto de sustentação da investigação está em compreendermos a estética como dimensão da sensibilidade e da criatividade, que envolve todos os sentidos, a percepção humana e a formação como uma busca vital do saber-viver, da felicidade, do sentido e do conhecimento (JOSSO, 2002). A importância de abrirmos espaço para as narrativas de formação estética é evidenciada como oportunidade de rememorarmos, de indagarmos sobre aquilo que a memória guarda e refletirmos sobre o nosso estar no mundo. No ato de rememorar podem emergir histórias que contam experiências marcantes da formação daquele que lembra, nas quais também podem se projetar os percursos de sensibilidade, de formação e de afinação de sentidos que contribuem para dar sentido à vida vivida e seguir em frente, uma vez que busca reinventar a vida por viver.

Dentro desse campo conceitual, a realização de encontros-ateliê com professoras de Educação Infantil, autorreferenciadas negras, é o principal dispositivo de produção de dados e de oportunidade formativa, sobre o qual falaremos a seguir.

\title{
NOS ENCONTROS-ATELIÊ: A POÉTICA DE ARTISTAS NEGRAS COMO FIOS PARA OUTRAS PARTIDAS
}

\author{
Normalizamos palavras e imagens que nos \\ informam quem pode representar a condição \\ humana e quem não pode. A linguagem \\ também é transporte de violência, por isso \\ precisamos criar novos formatos e narrativas. \\ Essa desobediência poética é descolonizar. \\ Grada Kilomba (2019, n. p.)
}

A proposição de encontros-ateliê como dispositivo de produção de dados biográfico-narrativos advém do diálogo com o trabalho de investigação (auto)biográfica desenvolvido por Ostetto e Bernardes (2019). Referenciados em Delory-Momberger (2006), Paulo Freire (2004) e Formenti (1996), e concebidos como espaços de narrativa de si, os encontro-ateliês acontecem na articulação de quatro movimentos, não lineares ou sequenciais, mas integrativos (OSTETTO; BERNARDES, 2019). Na investigação realizada pelas referidas autoras, um primeiro movimento focou a ativação das 
memórias, mediada por imagens de arte, com o objetivo de abrir espaço para a enunciação e a acolhida de narrativas orais das participantes. Depois, ao visar a imersão nas histórias de vida evocadas, o segundo movimento foi constituído pela proposição de vivências corporais e pela produção de atividades plástico-pictóricas, com o intuito de instigar o exercício de ir ao (re)encontro de lembranças - de percepções, de gostos, de olhares, de experimentações sensoriais -, consideradas marcas da formação de sua sensibilidade. O terceiro movimento voltou-se "[...] ao exercício-esboço de escrita de si, projeto de narrativa de formação, para chegar mais perto das experiências estéticas constituintes de sua história com a arte, a cultura, a natureza, com o intuito de produzir o Diário de memórias e de miudezas" (OSTETTO; BERNARDES, 2019, p. 167). Para finalizar o ciclo, em um movimento de síntese, o tempo foi dedicado para articulação da narrativa de si.

$\mathrm{Na}$ investigação, as pesquisadoras provocaram a ação de rememorar não apenas por meio da palavra, mas também por diferentes linguagens expressivas. Até chegar à escrita de si, os participantes da pesquisa foram convidados a pensar sobre suas experiências e dizer sobre elas, ao experimentar materiais expressivos - desenho, colagem, pintura, fotografia -, geralmente associados ao campo artístico, de forma a ativar a criatividade e ampliar os modos de dizer-se. Segundo as autoras, apoiadas em Formenti (1996), a dimensão poética e o contato com materialidades, potencialmente expressivas, fertilizam e amplificam os modos de cada participante falar de si.

Ao assumirmos esses elementos como coordenadas, nossa pesquisa fez-se no diálogo com mulheres negras, que atuavam como professoras na Educação Infantil. Os dados que aqui apresentamos se referem à etapa preliminar, fase-piloto. Atendendo aos objetivos propostos na pesquisa, houve consulta inicial sobre autodeclaração racial e produção cultural afro-brasileira. Neste contexto, a realização de encontros-ateliês narrativos contou com a participação de cinco mulheres negras, que atuam ou atuaram nos últimos dez anos (2010-2020) como professoras na educação infantil.

Para além das colaboradoras no projeto-piloto, a pesquisa em andamento, na sua primeira fase, contou com a participação de 36 professoras que responderam a um questionário de sondagem, com questões gerais pertinentes à temática abordada e também sobre seu pertencimento étnico-racial. Para uma caracterização geral das respondentes: todas do gênero feminino. apresentam idade entre 27 e 61 anos; do total, $88,2 \%$ nasceram no Estado do Rio de Janeiro, apenas 47,2\% residem na cidade de Niterói. Quanto ao local de trabalho, representam 20 entre as 43 Unidades Municipais de Educação Infantil da Rede Pública da Cidade de Niterói. Do total, 28,9\% atuam como professora há mais de 20 anos. Tendo $65,8 \%$ atuado com todas as faixas etárias de crianças, de zero a cinco anos.

As respondentes, ao serem questionadas de forma ampla sobre seu pertencimento étnico-racial, tendo em vista sua autoidentificação, declararam-se: $52,8 \%$ brancas e 47,2\% não-brancas. Da classificação das 36 participantes, temos: 7 (sete) pardas, 5 (cinco) pretas, 4 (quatro) negras, 1 (uma) multirracial e 19 (dezenove) brancas.

Para a participação na segunda fase da pesquisa, buscava-se por colaboradoras negras, autodeclaradas pretas ou pardas em suas respostas. No questionário, fez-se o uso da autoatribuição de pertença racial, no qual o próprio sujeito da classificação declara cor/raça, de acordo com Osorio (2003). Considerando a prática de pesquisadores e também do movimento social, neste trabalho a categoria negra contempla o agregado 
das pessoas que responderam às cores preta e parda, e também, à categoria negra e multirracial.

A escolha por mulheres negras se deu pelas inúmeras dificuldades estruturais existentes para seu reconhecimento e valorização. Uma vez que a luta das mulheres negras contra a opressão de gênero e de raça vem desenhando novos contornos para a ação política feminista e antirracista (CARNEIRO, 2003). Acredita-se que relatos biográficos de mulheres negras podem provocar a discussão sobre formação de professores, especialmente no processo de reeducação das relações étnico-raciais para toda a nação brasileira.

O contato com as professoras deu-se por meio de convite partilhado nas redes sociais. Das professoras que responderam afirmativamente ao convite, cinco correspondiam aos critérios estabelecidos e concordaram em colaborar. Para efetivar sua participação, elas assinaram o Registro de Consentimento Livre Esclarecido, aprovado pelo Conselho de Ética e Pesquisa em Humanas da Universidade que abriga a pesquisa, o qual foi encaminhado via e-mail.

Haja vista o contexto pandêmico, que impôs o distanciamento social, os encontros reuniram as participantes pelas janelas virtuais, via plataforma Google Meet. Com duração de uma a duas horas cada, os cinco encontros-ateliê foram realizados entre os meses de julho e agosto de 2020. As sessões foram gravadas e, posteriormente, transcritas.

Quando pretendemos provocar e acolher narrativas de vida, a partir da rememoração sobre tempos, espaços, movimentos, relações, encontros, desencontros, experiências formadoras, implicados no campo da sensibilidade, o cuidado com o contexto no qual as narrativas serão enunciadas torna-se, mais do que nunca, um aspecto fundamental. Com esse cuidado, o desafio da virtualidade imposta e também com a intencionalidade de movimentar conteúdos biográficos de cada participante a partir de conteúdos artístico-culturais com marcas identitárias negras, os encontrosateliê foram desenvolvidos em torno da poética de artistas negras. Obras e materiais das artistas que se fizeram nossas interlocutoras foram todas apresentados por meio de ferramentas digitais.

Entre tantas mulheres brasileiras contemporâneas que, pela arte, afirmam sua existência no mundo, compõem o roteiro das conversas com as professoras: Conceição Evaristo, Rosana Paulino e Lia de Itamaracá, três mulheres importantes para a arte e a cultura brasileira, que possuem histórias singulares e diversas, expressas nas produções e nas linguagens artísticas com que trabalham.

Maria da Conceição Evaristo de Brito, romancista, contista e poeta, nascida na cidade de Belo Horizonte, em 1946, no estado de Minas Gerais. Em sua poesia, ela pontua sua ancestralidade de maneira crítica. Toma partido da cultura negra de forma lírica e política. Entre suas obras, Poemas da recordação e outros movimentos (EVARISTO, 2017) é uma antologia poética em que a autora mineira tece memória, feminilidade e resistência negra, a partir de suas "escrevivências", termo cunhado por ela para dizer que toda sua escrita é fruto de suas experiências de vida.

Rosana Paulino, artista visual, pesquisadora e educadora, nasceu na cidade de São Paulo, em 1967. Ela se destaca por fazer da imagem impressa um meio estruturador 
SILVA, G. D. de B.; OSTETTO, L. E.

de seu pensamento visual, desdobrando-a em diferentes linguagens. De toda a sua obra, salientamos Parede da memória (1994-2015). A partir de uma investigação da própria identidade, na caixa de fotos de sua família, essa obra traz 11 retratos de família que se multiplicam em 1.500 "patuás" - pequenas peças usadas como amuletos de proteção por religiões de matriz africana. É inspiração também como intelectual, por ser a primeira negra a ter Doutorado em Artes no Brasil.

Maria Madalena Correia do Nascimento, a Lia de Itamaracá, dançarina, compositora e cantora de ciranda brasileira, nasceu na llha de Itamaracá, em Pernambuco, no ano de 1944. Ainda criança, começou a participar de rodas de ciranda. Trabalhou como merendeira em escola pública. Dedicou-se a cantar e a compor cocos de roda e maracatu. Destacamos, entre suas composições, Minha ciranda e Eu sou Lia. A mais célebre cirandeira do Brasil é patrimônio vivo de Pernambuco.

Apoiados na história e na produção dessas artistas negras, os encontros-ateliê transcorreram como conversas-reflexões-rememorações-narrativas, mobilizados pela articulação entre fruição artística e processos expressivos, com a intenção de inspirar processos e modos de falar de si criativos. Essa perspectiva fundamenta-se no fato de que compartilhar repertórios artístico-culturais, desde o ponto de vista de artistas negras, contribui para a ampliação de referências e de valorização pessoal e profissional das participantes. Como diz Adolfo Achinte (2017), a arte como mecanismo de autorrepresentação, de autossignificação e de construção de novas simbologias contribui para evidenciar a pluralidade de existências que se encontram e desencontram no cenário multicor da contemporaneidade.

$\mathrm{Na}$ abertura de cada encontro-ateliê, utilizamo-nos de poesias, de músicas e de imagens de obras de artes visuais, selecionadas do acervo das artistas Conceição Evaristo, Rosana Paulino e Lia de Itamaracá. Obras e histórias de suas vidas foram apresentadas às participantes no decorrer dos encontros sequenciais, cada qual com um convite à conversa: Quem conhece essa artista? Quais obras conhece?

No ambiente virtual, à medida que o grupo ia se conhecendo e, também, as artistas, a partir de uma pergunta-guia - "Como esta artista e sua arte conectam-se à sua história de vida?" -, fez-se o encorajamento para a reflexão de sua própria história, sobre as marcas de identidade que fizeram/fazem parte de seu percurso e, por fim, cada uma escreveu sobre si.

Na dinâmica construída no momento da escrita de si, as câmeras foram fechadas enquanto escreviam. À medida que concluíam seus registros, as participantes abriam as câmeras e rompiam o silêncio, dando visibilidade às suas histórias por meio da leitura de suas narrativas e na articulação de outras histórias compartilhadas na oralidade e na interlocução.

$\mathrm{O}$ encontro com a produção das três artistas, que nos acompanharam e inspiraram, provocou o reconhecimento dos seus repertórios artístico-culturais. Suas narrativas apontaram, inclusive objetivamente, elementos que são referências e que marcam sua sensibilidade: bongô, tambor, turbante, moringa, saias das rodas de jongo, espelhos e fotografias dos cabelos que se modificaram ao longo da vida; fotografias de viagens a Salvador, Berlim, Cuba.

Os sentidos despertados a partir do encontro com as poéticas de artistas negras, revelados em suas narrativas, afirmaram existências múltiplas de experiências que, 
apenas pela rememoração, pela escuta e pela partilha, materializaram-se em histórias (con)fiadas.

\section{ELEMENTOS PARA PEDAGOGIAS DA DIVERSIDADE, DECOLONIAIS E DE RE-EXISTÊNCIA}

Quando não souberes para onde ir, olha para trás e saiba pelo menos de onde vens.

Provérbio africano, citado por Gonçalves (2020,

O cenário pandêmico nos impôs o cumprimento de recomendações éticas e sanitárias, como o devido distanciamento social e nos fez abrir janelas à (re)invenção dos modos de viver, de educar e também de pesquisar. Consideramos prudente realizar um projeto-piloto, um estudo prévio, que contou com a colaboração de professoras com as quais tínhamos contato a partir do trabalho realizado na Educação Infantil em unidades públicas do estado do Rio de Janeiro.

O estudo, já em seu projeto-piloto, mostrou-se pertinente e necessário, pois a partir dele, percorrendo os desafios da errância e da constituição do campo de pesquisa com as participantes, foi possível exercitar o olhar e todos os sentidos de uma pesquisaformação, sendo oportuno experimentar os dispositivos escolhidos e analisar seus limites e possibilidades.

Os dados, advindos da transcrição dos áudios dos encontros-ateliês, estão sendo discutidos em perspectiva interpretativa, a partir dos aportes teóricometodológicos da pesquisa narrativa (auto)biográfica. Dado o valor heurístico das narrativas e a análise interpretativa-compreensiva (RICOEUR, 1996), busca-se evidenciar as trajetórias formativas e os sentidos que cada sujeito atribui a sua vida, considerando o modelo dialógico proposto por Pineau e Le Grand (2012). É pertinente indicar, também, que o tratamento dos conteúdos biográficos perfaz uma leitura em três tempos, como sugerido por Souza (2004): Leitura Articulada, Leitura Temática e Leitura Interpretativa. .

Os encontros-ateliês realizados como parte preliminar da pesquisa ficaram marcados como espaço para a interação, para a partilha de histórias, para experimentar e acolher outros modos de ver e para o reconhecimento de questões comuns. Mais do que os conteúdos identificados nas narrativas orais, escritas e plástico-expressivas produzidas pelas professoras, a serem analisados como dados, em primeiro plano identificamos palavras-chave: interação, partilha, experimentação, reconhecimento, histórias e identidades. De per si, estariam, nesse momento, colocados aí elementos sutis para compor uma pedagogia da diversidade, tecida na práxis, politicamente comprometida com a reinvenção de narrativas de si.

Ainda que inicialmente fosse um grupo desconhecido, a reunião virtual se tornou um espaço de fortalecimento e de encorajamento para as trajetórias narradas. $\mathrm{O}$ pertencimento étnico-racial, traço que ligava as cinco histórias de vida, foi discutido na problematização da negritude desde a primeira reunião. A partir das questões mobilizadoras, trazidas pelas poéticas das artistas apresentadas, foi possível identificar nas conversas alguns tempos, alguns espaços, algumas pessoas e alguns hábitos culturais que atravessam a formação estética de professoras de Educação Infantil negras 
SILVA, G. D. de B.; OSTETTO, L. E.

- como os elementos de seus repertórios artístico-culturais: objetos simples como panela e colher acenderam memórias afetivas; o bongô, tambor, turbante, moringa falavam de identidade; saias das rodas de Jongo e da Linha do Oriente contavam expressões culturais das quais participavam; espelhos e fotografias dos cabelos que se modificaram ao longo da vida deixavam entrever a história de enfrentamento e o processo de assumir-se negra; lembranças dos deslocamentos por Salvador, Cuba e Berlim mostraram-se em fotografias repletas de significado.

Foi possível identificarmos marcas da cultura africana e afro-brasileira na história de vida das professoras, as quais compunham sua formação estética. Por exemplo, a oralidade: foi um elemento que animou a partilha de lembranças adormecidas e um canal para a manifestação da inteireza de todas as participantes nas conversas - suas dores, suas alegrias, suas conquistas, seus dramas, suas superações e suas resistências. Desde o início, ao citar-se "professoras de educação infantil negras", seguiram-se relatos de reconhecimento da negritude entre mulheres que, com sensibilidade, contaram sobre a sua presença na sociedade.

No desenvolvimento dos encontros, cada uma foi profundamente tocada pela rememoração: o choro e o riso compartilhados em muitos momentos comprovaram que algo acontecia ali, no encontro, na enunciação da palavra, na partilha das memórias, na escuta das histórias. As tensões também estavam presentes, especialmente relacionadas à religiosidade: Umbanda, candomblé, pentecostal, irreligião eram crenças professadas pelas participantes. Nesse ponto, vieram para os encontros símbolos de São Benedito, Nossa Senhora Aparecida, Santa Sara dos Ciganos, Congá de Umbanda, cartas psicografadas. No respeito constituído no espaço de escuta e de narrativa cultivado, os símbolos das crenças circularam com diferentes representações no grupo e expandiram a reflexão.

As narrativas orais das participantes sobre o modo como vivem, compreendem e resolvem seus problemas sociais, incluindo a discriminação e o racismo, carregavam uma densa carga emocional. Contudo, a atividade biográfica, entendida como uma das formas privilegiadas de atividade mental e reflexiva, mostrou-se como dispositivo válido para o sujeito poder representar e compreender a si mesmo, implicado no seu ambiente social e histórico projetado nos discursos da memória.

As produções das artistas negras escolhidas para fazerem parte das conversas contribuíram realmente para o exercício de rememoração e para a construção de narrativas de si. A experiência evidenciou que a dimensão estética, como elemento constitutivo do humano, é imprescindível na formação de professores e pode contribuir para educar as relações étnico-raciais na Educação Infantil. Em se tratando de mulheres negras, professoras, as poéticas de artistas negras partilhadas esboçaram movimentos que demonstram a contribuição do encontro-ateliê não apenas para ampliar as referências artístico-culturais, mas também para afirmar as referências então identificadas nos traços da ancestralidade impregnados na vida vivida, porém nem sempre visibilizadas.

Pensar pedagogias da diversidade, é pensar pedagogias de re-existência, no sentido emprestado por Achinte (2017, p. 41):

[...] la re-existencia como los dispositivos que las comunidades crean y desarrollan para inventarse cotidianamente la vida y poder de esta manera confrontar la realidad establecida por el proyecto 
hegemónico que desde la colonia hasta nuestros dias ha inferiorizado, silenciado y visibilizado negativamente la existencia de las comunidades afrodescendientes.

As experiências que marcam a formação sensível de professoras negras, mapeadas por meio de narrativas autobiográficas tecidas no encontro com a poética de artistas negras, referendam o paradigma ético-estético e reiteram a contribuição da proposta de encontros-ateliê como uma direção fecunda para pensar e fazer formação de professores da Educação Infantil nas perspectivas da reinvenção da existência e de pedagogias da diversidade.

Artigo recebido em: 01/03/2021 Aprovado para publicação em: 14/10/2021

\section{EARLY CHILDHOOD EDUCATION, ETHNIC-RACIAL DIVERSITY AND AESTHETIC PRINCIPLES: CONTRIBUTIONS OF THE POETICS OF BLACK ARTISTS TO TEACHER TRAINING}

ABSTRACT: This paper presents a proposal for workshop-meetings, which were held with black Early Childhood Education teachers, with the aim of mapping their paths of aesthetic training. Structured around the sharing of poetics by black artists, the workshop-meetings were constituted as space-time for autobiographical narratives, in order to support the premise that it is necessary to open space for listening to narratives that affirm singular-plural (re)existences. Issues about ethnic-racial diversity and aesthetic principles in the proposals for Early Childhood Education are articulated and make up the context over which the discussion is woven. The focus is on teacher training, as it is understood that the proposition of pedagogies of diversity, decolonial and reexistence, necessarily passes through teaching and its repertoires.

KEYWORDS: Pedagogy of Diversity. Black Teachers. Teacher Training. Aesthetic Principles.

EDUCACIÓN INFANTIL, DIVERSIDAD ÉTNICO-RACIAL Y PRINCIPIOS ESTÉTICOS: CONTRIBUCIONES DE LAS POÉTICAS DE ARTISTAS NEGRAS A LA FORMACIÓN DOCENTE

RESUMEN: Este artículo presenta una propuesta de encuentros-talleres, que fueron realizados con docentes de Educación Infantil negras, con el objetivo de mapear sus caminos de formación estética. Estructurados en torno al compartir de poéticas de artistas negras, los encuentros-talleres se constituyeron como espacio-tiempo para narrativas autobiográficas, de modo a sustentar la premisa de que es necesario abrir espacio para la escucha de narrativas que afirmen (re)existencias singulares-plurales. Cuestiones sobre diversidad étnico-racial y principios estéticos en las propuestas para la Educación Infantil se articulan y componen el contexto en el que la discusión es tejida. El foco está en la formación docente, pues se comprende que la proposición de pedagogías de la diversidad, descoloniales y de reexistencia, pasa necesariamente por la docencia y sus repertorios. 
SILVA, G. D. de B.; OSTETTO, L. E.

PALABRAS CLAVE: Pedagogía de la Diversidad. Docentes Negras. Formación Docente. Principios Estéticos.

\section{REFERÊNCIAS}

ACHINTE, A. A. Prácticas creativas de re-existencia: más allá del arte... el mundo de lo sensible. Buenos Aires: Del Signo, 2017.

BÂ, A. H. A Tradição Viva. In: KI-ZERBO, J. (ed.). História geral da África, I: Metodologia e pré-história da África. 2.ed. rev. Brasília: UNESCO, 2010. p. 167-212.

BRASIL. Ministério da Educação. Secretaria da Educação Continuada, Alfabetização e Diversidade. Diretrizes curriculares nacionais para a educação das relações étnicoraciais e para o ensino de história e cultura afro-brasileira e africana na educação básica. Brasília: MEC/SECAD, 2004.

BRASIL. Parecer № 20, de 11 de novembro de 2009. Revisão das Diretrizes Curriculares Nacionais para a Educação Infantil. Brasília: Conselho Nacional de Educação, Câmara de Educação Básica, [2009a]. Disponível em:

http://portal.mec.gov.br/dmdocuments/pceb020_09.pdf. Acesso em: 10 fev. 2021.

BRASIL. Resolução N 5, de 17 de dezembro de 2009. Fixa as Diretrizes Curriculares Nacionais para a Educação Infantil. Brasília: Conselho Nacional de Educação; Câmara de Educação Básica, [2009b]. Disponível em:

http://www.seduc.ro.gov.br/portal/legislacao/RESCNE005_2009.pdf. Acesso em: 10 fev. 2021.

DELORY-MOMBERGER, C. Formação e socialização: os ateliês biográficos de projeto.

Tradução Maria Carolina Nogueira Dias e Helena C. Chamlian. Educação e Pesquisa, São Paulo, v. 32, n. 2, p. 359-371, maio/ago. 2006. DOI: http://dx.doi.org/10.1590/S151797022006000200011

DELORY-MOMBERGER, C. Biografia e educação: figuras do indivíduo-projeto. Natal: UFRN; São Paulo: Paulus, 2008.

EVARISTO, C. Poemas da recordação e outros movimentos. Rio de Janeiro: Malê, 2017. FIAR Círculo de Estudo e Pesquisa Formação de Professores, Infância e Arte. Fiar com...propostas de educação antirracista (17). Niterói, 28 ago. 2020. Facebook: @fiar.pesquisa. Disponível em: https://www.facebook.com/fiar.pesquisa/photos/306048780822233. Acesso em: 15 fev. 2021.

FORMENTI, L. La storia che educa: contesti, metodi, procedure dell'autobiografia educativa. Rivista Adultità, Milano, n. 4, p. 83-100, out. 1996.

Inter-Ação, Goiânia, v.46, n.3, p. 1475-1491, set./dez. 2021. Disponível em: <http://dx.doi.org/10.5216/ia.v46i3.67959>. 
FREIRE, P. Pedagogia da autonomia. Saberes necessários à prática educativa. 30. ed. São Paulo: Paz e Terra, 2004.

FREIRE, P. Política e educação: ensaios. 5. ed. São Paulo: Cortez, 2001.

GOMES, N. L. O movimento negro educador. Saberes construídos na luta por emancipação. Petrópolis: Vozes, 2017.

GONÇALVES, A. M. Um defeito de cor. 23. ed. Rio de Janeiro: Record, 2020.

HERMANN, N. Ética e estética: a relação quase esquecida. Porto Alegre: EDIPUCRS, 2005.

HOOKS, B. Anseios: raça, gênero e políticas culturais. São Paulo: Elefante, 2019.

JOSSO, M. C. Experiências de vida e formação. Lisboa: Educa, 2002.

KILOMBA, G. "O colonialismo é a política do medo. É criar corpos desviantes e dizer que nós temos que nos defender deles". [Entrevista cedida a] Joana Oliveira. El País, São Paulo, 12 set. 2019. Disponível em:

https://brasil.elpais.com/brasil/2019/08/19/cultura/1566230138_634355.html. Acesso em: 10 fev. 2021.

MARTINS, M. C.; LOMBARDI, L. M. A arte na pedagogia e a formação do professor para educação infantil e anos iniciais: inquietações e esperanças. Trama Interdisciplinar, São Paulo, v. 6, n. 2, p. 23-36, maio/ago. 2015.

OSÓRIO, Rafael Guerreiro. O sistema classificatório de "cor ou raça" do IBGE. Brasília: IPEA, 2003. (Texto para discussão, 996).

OSTETTO, L. E. Sobre a organização curricular da Educação Infantil: conversas com professoras a partir das Diretrizes Curriculares Nacionais. Revista Zero-a-Seis, Florianópolis, v. 19, n. 35, p. 46-68, jan./jun. 2017. DOI: https://doi.org/10.5007/19804512.2017v19n35p46

OSTETTO, L. E. Com o pensamento do coração, entrelaçando docência e formação estética. Atos de Pesquisa em Educação, Blumenau, v. 14, n. 1, p. 57-76, jan./abr. 2019. DOI: http://dx.doi.org/10.7867/1809-0354.2019v14n1p57-76

OSTETTO, L. E.; BERNARDES, R. K. Infâncias em diários de formação estética: narrativas de estudantes de pedagogia e de arte. Revista @mbienteeducação, São Paulo, v. 12, n. 2, p. 164-180 maio/ago. 2019. DOI: https://doi.org/10.26843/ae19828632v12n22019p164a180 
SILVA, G. D. de B.; OSTETTO, L. E.

OSTETTO, L. E.; SILVA, G. D. B. Formação docente, Educação Infantil e arte: entra faltas, necessidades e desejos. Revista Educação e Cultura Contemporânea, Tubarão, v. 15, n. 41, p. 260-287, jan./jun. 2018. DOI: http://dx.doi.org/10.5935/2238-1279.20180077

PINEAU, Gaston; JEAN-LOUIS, Le Grand. As histórias de vida. Natal: ÉDUFRN, 2012.

RICOEUR, Paul. Teoria da interpretação. Trad. Artur Morão. Lisboa: Edições 70, 1996.

SOUZA, Elizeu. C. O conhecimento de si - narrativas do itinerário escolar e formação de professores. Tese (Doutorado em Educação). Universidade Federal da Bahia, faculdade de Educação, 2004.

VECCHI, V. Arte y creatividad en Reggio Emilia: el papel de los talleres y sus posibilidades en educación infantil. Madrid: Ediciones Morata, 2013.

VECCHI, V. I linguaggi poetici come contrapposizione alla violenza. In: REGGIO CHILDREN. (org.). Bambini arte artisti. Reggio Emilia: Reggio Children, 2007. p. 137-143.

Greice Duarte de Brito Silva: Doutoranda e Mestre em Educação pela Universidade Federal Fluminense (UFF). Licenciada em Pedagogia pela AVM Faculdade Integrada. Professora do Ensino Básico, Técnico e Tecnológico na Universidade Federal Fluminense lotada no Colégio Universitário Geraldo Reis / COLUNI UFF. Pesquisadora no Círculo de Estudos e Pesquisa Formação de Professores, Infância e Arte / Faculdade de Educação UFF.

Orcid: https://orcid.org/0000-0002-8655-8034

E-mail: greicedbrito@gmail.com

Luciana Esmeralda Ostetto: Professora da Faculdade de Educação - Universidade Federal Fluminense. Atua na graduação (curso de Pedagogia) e na pós-graduação (Mestrado e Doutorado em Educação). Foi professora do Centro de Educação Universidade Federal de Santa Catarina (1995-2012). Possui doutorado em Educação pela Universidade Estadual de Campinas (2006), mestrado em Educação pela Universidade Federal de São Carlos (1992) e graduação em Pedagogia pela Universidade Federal de Santa Catarina (1985). Coordenadora do FIAR - Círculo de estudos e pesquisa formação de professores, infância e arte (Faculdade de Educação da UFF). Pós-doutorado na Universidade de Évora (2018-2019), com bolsa CAPES / Programa Professor Visitante no Exterior.

Orcid: https://orcid.org/0000-0002-1948-5090

E-mail: lucianaostetto@id.uff.br

Este periódico utiliza a licença Creative Commons Attribution 3.0, para periódicos de acesso aberto (Open Archives Initiative - OAI). 